\title{
Analysis of Traffic Congestion on Nigerian Roads (A Case Study of Sango T Junction, Ibadan, OYO STATE)
}

\author{
E. A. Irunokhai \\ Federal College of Wildlife \\ Management, New Bussa, \\ Niger State, Nigeria
}

\author{
J. O. Onihunwa \\ Federal College of Wildlife \\ Management, New Bussa, \\ Niger State, Nigeria
}

\author{
E. K. Oni \\ Federal Polytechnic Ede, \\ Ede, Osun State, Nigeria
}

\author{
J. O. Adigun \\ Federal College of Wildlife Management, New \\ Bussa, \\ Niger State, Nigeria
}

\author{
O. S. Dada \\ Federal University of Kashere, \\ Gombe state, Nigeria
}

\begin{abstract}
One of the major characteristic of every living thing is movement and transportation by road has been a major means of transportation long decades ago and this has been fully accompanied with road traffic congestion due to the increase population of people living in the urban areas. Mobility through vehicle opens urban-rural movement and with increase in population size along the vehicle that cater this movement has led to increase in rate of traffic and congestion. Traffic congestion is the impedance of vehicles imposed on each other due to speed flow relationship in conditions where the use of transport system approaches capacity. Nigeria is not exempted from traffic congestion, Sango $T$ junction in the city of Ibadan was taken as a case study. In order to ascertain the average waiting time of vehicles during road traffic jam, traffic situation using direct observation and time count down of vehicle within the traffic queue was employed and traffic data was collected. Total numbers of vehicles and the specific waiting time for periodic hour was documented, this included both peak and off peak traffic periods and the data obtained was analysed using means plot, t-test and analysis of variances. Based on the result of the analysis obtained, it is vividly deduced that the peak period of traffic is in the morning even though the average waiting time for the road users in the evening was higher compared to the morning period, it was also discovered that the traffic flow does not have much significant difference between its peak and off peak period.
\end{abstract}

\section{General Terms}

Data mining

\section{Keywords}

Traffic, Roads, Congestion, Time, Vehicle.

\section{INTRODUCTION}

Transportation is an important aspect of human civilization as it reflects the economic level and technological advancement of a given society [1]. One of the characteristics of human being is mobility. Men depends on about four means of transportations; the road, air, water and through the rail. However, among all these transportation facilities, automotive vehicles are still the most adopted due to its comfort and practicality [2]. The road aspects have the most significant impact and dependencies since it is the least costly means of transportation including the price factor of acquiring vehicle compare to other means of transportation. Traffic congestion is the impedance of vehicles imposed on each other due to speed flow relationship in conditions where the use of transport system approaches capacity [3]. Vehicle traffic is an inevitable and continuous event occurring daily especially at urban areas, due to rate of inflow of vehicles and road been the major means of transportation [4]. Mobility through vehicle opens urban-rural movement and with increase in population size along the vehicle that cater this movement has led to increase in rate of traffic and congestion. Traffic congestion arises when the rate of traffic flow is beyond the road capacity and the rate of congestion increases along traffic road junctions where several vehicles tries to manoeuvre to their various destination. Traffic congestion has adverse effect on the environment and its society. It creates several negative concerns for the environment and society such as increasing in number of traffic accidents, economic impacts, and high levels of greenhouse emissions [5]. In cities, where the number of vehicles continuously increases faster than the available traffic infrastructure to support them, congestion is a difficult issue to deal with and it becomes even worse in case of car accidents. This problem affects many aspects of the modern society, including economic development, traffic accidents, increase in greenhouse emissions, time spent, and health damages [6]. Traffic rules has been set which every road commuter must adhere to but as the traffic congestion rate increases, road users tend to violating these rules in order to bypass traffic jams with the motor cyclist been the highest traffic violators especially in the developing countries of the world. This uncivilized behaviour has led to the increase of road accidents and loss of lives.

\subsection{Significant of the Study}

This study has great importance to various departments of road traffic/safety agencies and environmental health organizations as it provides fundamental insight of the traffic situation within the case study area. This research also provides awareness to the populace on the time commuters spend/waste in plying the road.

\subsection{Research Hypothesis}

$\mathrm{H}_{0} 1$ : There is no significance difference in the average waiting time of road users in the morning and evening

$\mathrm{H}_{0} 2$ : There is no significance difference in the average waiting time of road users within all time zones selected. 


\section{LITERATURE REVIEW}

There are a number of specific circumstances that cause or aggravate congestion. Most of them reduce the capacity of a road at a given point or even over a certain length, or increase in the number of vehicles required for a given volume of people or goods [7]. Delayed removal of broken down vehicle on the road, accidents and violation of traffic rules includes causes of traffic congestion. Besides these palpable causes, employment patterns, income levels and poor maintenance of roads, shoddy works due to poor supervision and monitoring, corruption and the negligence of duty bearers may cause road traffic congestion indirectly [8].

There have been lots of research works on the vehicle traffic congestions. [1] worked on health effect of congestion on the road users. The research highlighted that congestion has physical, mental and psycho social impact on the road users. It was even discovered that traffic congestion increases on road and near-road pollutant exposure due to increased time in traffic. Traffic congestion causes cars to slow down or even to stop. When cars are idle, fuel are still burnt and fuel emissions are released into the atmosphere. And in the aspect of traffic violation and safety, driving safety is affected by various factors, which together determine the level of traffic safety or risk. Such factors include driver characteristics, road layout, the design of the car and weather condition. However, most road accidents are attributed to 'human factor' most especially to road safety violations [10]. Lots of evidence have been documented based on driver behaviour key role played in traffic safety as it is important in traffic accident prevention. Attitudes have been revealed to be significant predictors of driver behaviour in high-income countries and have also been identified to indirectly affect involvement in traffic accidents [11]. Nigeria has been consistently being ranked as having the highest incidents of road traffic accidents in the world for obvious reasons in addition to known causes of accidents across the globe which include very bad road arising from poor maintenance culture and poor road management [12]. And Due to the traffic congestions, Enterprises have to account for the amount of fuel to be used during the period on traffic and also the amount of time that would have been taken while on traffic. All these would then be factored in pricing a given product then passed on to the end consumer of the product [13].

\section{METHODOLOGY}

In order to ascertain the waiting time of commuters and vehicles during road traffic jam, traffic situation using direct observation and time count down of vehicle within the traffic queue was employed and traffic data was collected. Total numbers of vehicles and the specific waiting time for periodic hour was documented, this included both peak and off peak traffic periods (7:30 a.m. - 8:30a.m.; 8:30 a.m. - 9:30a.m.; 9:30 a.m. - 10:30a.m.; 4:00 p.m. - 5:00p.m. and 5:00 p.m. 6:00p.m.). The road users' vehicle types were not classified in the study and these include motor cycle, heavy trucks, private and commercial cars and busses. The procedures and processes involved were supervised and validated by the traffic unit of the Nigerian police.

The T-junction located at Sango, Ibadan the capital of Oyo state in Nigeria was purposively selected for the study. Sango, Ibadan has a geographical coordinate $7^{0} 25^{\prime} 39^{\prime \prime}$ North, $3^{0} 52^{\prime}$ 49" East. Fig. 1. shows the map of the area. The selected Tjunction is a very busy one as it connects up to three metropolitan cities of the state including the Nigeria Premier University of Ibadan and the Polytechnic of Ibadan. The Tjunction connects Sango to Mokola, UI/Agbowo and Elewure/Mokola road axis. The traffic situation of this area was observed during the earlier stated periods.

\section{RESULTS AND DISCUSSION.}

Table 1. Average waiting time for road users in the morning and evening

\begin{tabular}{|c|c|c|c|c|}
\hline Variables & $\begin{array}{c}\text { Mean } \\
\text { (minute } \\
\text { s) }\end{array}$ & df & $\begin{array}{c}\text { Mean } \\
\text { differenc } \\
\mathbf{e}\end{array}$ & $\begin{array}{c}\text { p- } \\
\text { value }\end{array}$ \\
\hline $\begin{array}{c}\text { Average waiting } \\
\text { time in the } \\
\text { morning }\end{array}$ & 0.9724 & 28 & 0.084 & 0.431 \\
\hline $\begin{array}{c}\text { Average waiting } \\
\text { time in the evening }\end{array}$ & 1.057 & & & \\
\hline
\end{tabular}

The result of the analysis presented in Table 1 shows that the average waiting time for road users in the evening (1.057) was more than the one in the morning (0.9724), however the average waiting time difference was not shown to be significant $(\mu>0$ and $p>0.05)$, hence this cannot conclude that average waiting time in the evening is significantly higher for road users in the evening as compared to average waiting time experienced in the morning.

Fig. 2 shows that waiting time for a road user was highest between 7:30 a.m. and 8:30 a.m. while road users had to wait least between 8:30 a.m. and 9:30a.m. Even though the average waiting time for users within the various specified time interval varies, however, there is need to test the level of significance of the variation between mean average waiting time at the specific time intervals, this is presented in table 2 . 


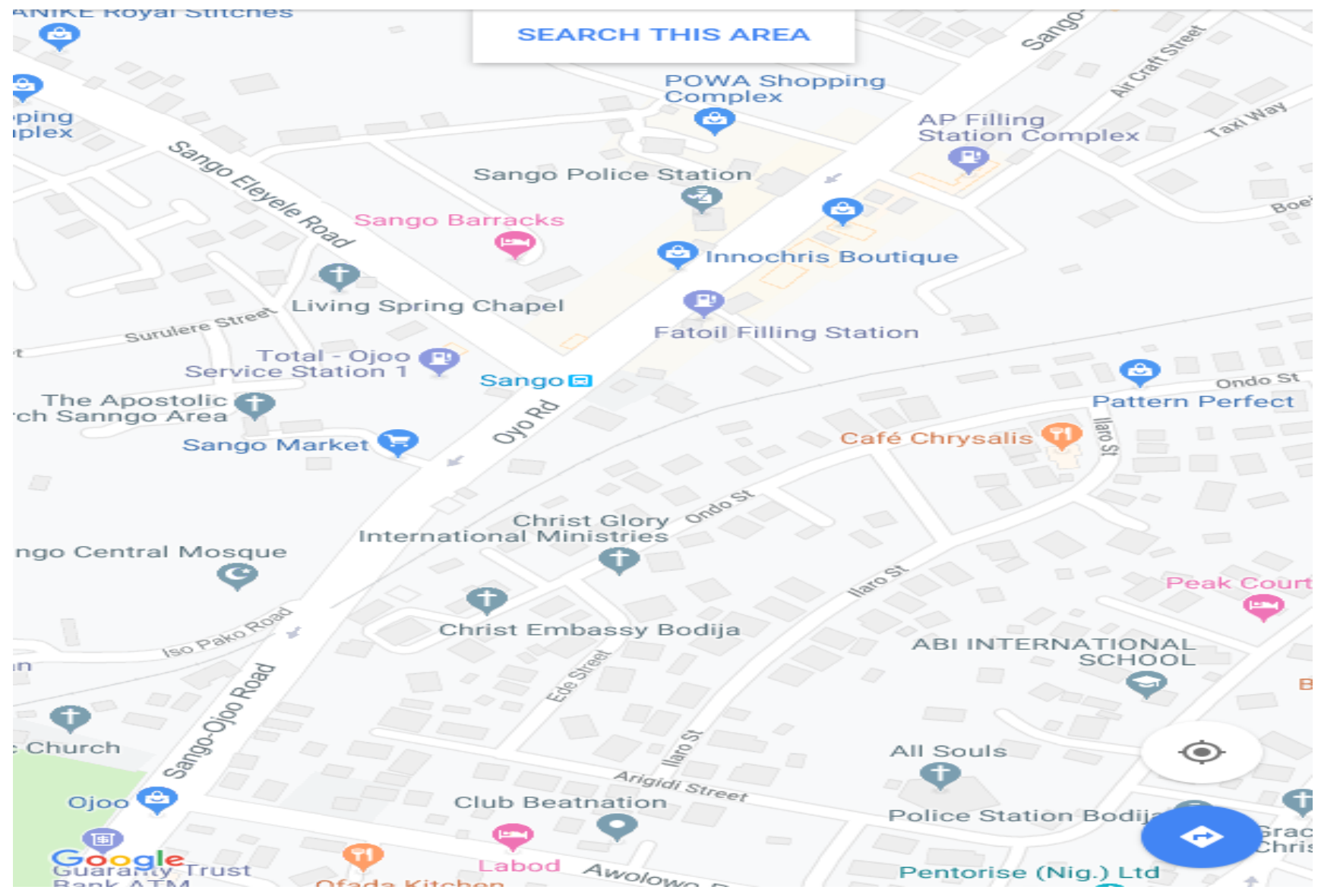

Fig 1: Map of Sango T-Junction (source: Google map)

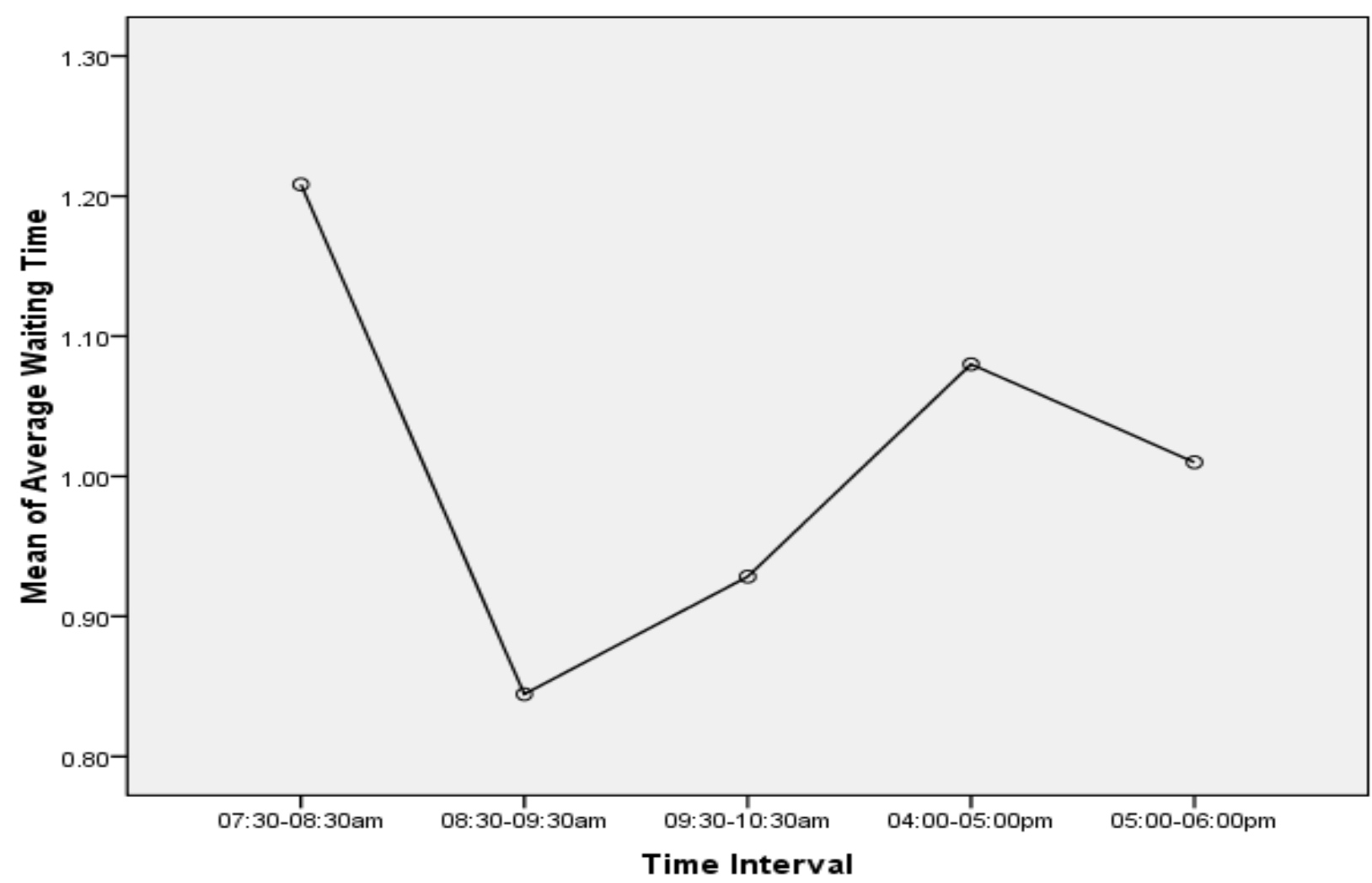

Fig 2: Means plot of average waiting time across all time zones selected 
The result of the analysis presented in table 2 shows that average waiting time across all time interval selected (07:3008:30am; 08:30-09:30am; 09:30-10:30am; 04:00-05:00pm and 05:00-06:00pm) were not significantly different from each other $(p>0.05)$ hence conclusion cannot be reached that road users wait more at specific time as compared with other time. However, more specific visualizations of the result are shown in fig. 2.

Table 2: Average waiting time across the time zones selected

\begin{tabular}{|c|c|c|c|c|c|}
\hline & $\begin{array}{c}\text { Sum of } \\
\text { Squares }\end{array}$ & Df & $\begin{array}{c}\text { Mean } \\
\text { Square }\end{array}$ & F & $\begin{array}{c}\text { Sig } \\
\cdot\end{array}$ \\
\hline $\begin{array}{c}\text { Between } \\
\text { Groups }\end{array}$ & .548 & 4 & .137 & $\begin{array}{c}2.34 \\
6\end{array}$ & $\begin{array}{c}.08 \\
2\end{array}$ \\
\hline Within Groups & 1.459 & 25 & .058 & & \\
\hline Total & 2.006 & 29 & & & \\
\hline
\end{tabular}

Table 3: Summarised waiting time across the three junctions

\begin{tabular}{|c|c|c|c|}
\hline Axis & Mean & N & $\begin{array}{c}\text { Std. } \\
\text { Deviation }\end{array}$ \\
\hline $\begin{array}{c}\text { University of Ibadan(U.I) } \\
\text { /Agbowo Road Axis Traffic data }\end{array}$ & 34.1290 & 10 & 7.60293 \\
\hline Eleyele-Polytechic road axis & 36.0050 & 10 & 9.39382 \\
\hline Elewure-Mokola road axis & 37.5060 & 10 & 11.76204 \\
\hline Total & 35.8800 & 30 & 9.49918 \\
\hline
\end{tabular}

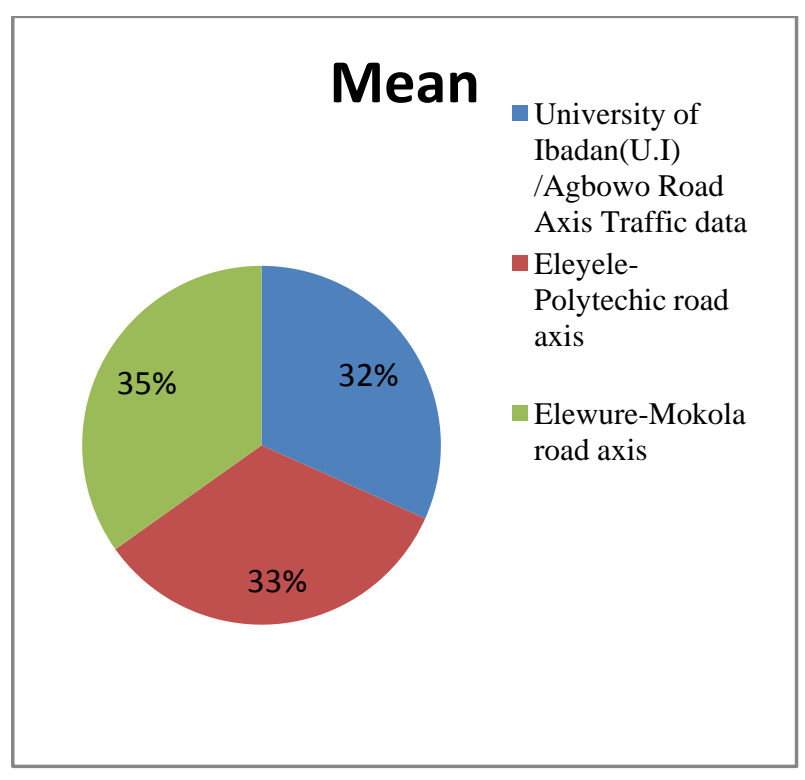

Figure 3: Means plot of average waiting at the three axis

The result of the analysis presented in table 3 shows the summarized waiting time of vehicles across the T-junction, which consist all the three roads. The obtained result shows the mean and its standard deviation. The graphical representation of the results is shown on figure 3. This depicts the percentage waiting time across each road.

\section{CONCLUSION AND RECOMMENDATION \\ 5.1 Conclusion}

Based on the result of the analysis obtained, it is vividly deduced that the peak period of traffic is in the morning (7:30$8: 30$ ) even though the average waiting time for the road users in the evening was higher compared to the morning period. And the result also shows the average waiting of vehicles of each road along the T-junction. Some factors that causes traffic congestion were not considered such as bad roads, accident, violation of traffic, vehicle parked along the road, broken down of vehicle but based on the report, the Sango T road junction traffic flow does not have much significant difference between its peak and off peak period, however there may be substantial changes when there are holidays and special events around the road axis.

\subsection{Recommendation}

Considering the results obtained and the situation of the case under study, the following are recommended:

1. Proper orientation and re-orientation program for road users on effective utilization of the road

2. Citing markets and malls/shops few kilometres away from the busy $\mathrm{T}$ road junction to reduce pedestrian and illegal parking

3. A pedestrian bridge across a path is needed.

4. Policy makers of the road transport management should initiate the provision of well-equipped quick traffic response unit to deal with frequent vehicle breakdowns on the road.

5. Proper road maintenance policy should be implemented

\section{REFERENCES}

[1] Awosusi, Ajoke Olukemi and Akindutire, I.O(2010), Urban Traffic Congestion and Its Attendant Health Effects on Road Users in Ado-Ekiti, Nigeria, An International Multi-Disciplinary Journal, Ethiopia. 4(4), pp. $434-446$

[2] Djahel S, Doolan R, Muntean G-M,. A communicationsoriented perspective on traffic management systems for smart cities: challenges and innovative approaches. IEEE Commun Surv Tutor 2015; 17(1): 125-151.

[3] Raheem S. B., Olawoore W. A., Olagunju1 D. P., Adeokun E. M. (2015). The Cause, Effect and Possible Solution to Traffic Congestion on Nigeria Road (A Case Study of Basorun-Akobo Road, Oyo State), International Journal of Engineering Science Invention 4(2).

[4] Irunokhai E.A. and Adigun J.O.(2019). Reducing Traffic Congestion and Violation Using Round Robin Algorithm, International Journal of Applied Research and Technology. 8(3): 50-55.

[5] De Souza AM, Yokoyama R, Boukerche A, et al. Icarus: improvement of traffic condition through an alerting and re-routing system. Comput Netw 2016; 110: 118-132.

[6] Allan M de Souza, Celso ARL Brennand, Roberto S Yokoyama, Erick A Donato, Edmundo RM Madeira and Leandro AVillas(2017), Traffic management systems: A classification, review, challenges, and future 
perspectives, International Journal of Distributed Sensor Networks, 13(4)

[7] Carlos, D. (1999): A Different Route to Health: Implications of Transport Policies. British Medical Journal 318 (7199): 1686-1689.

[8] Ellimah, M.A.K. (2009): The Albatross of Traffic Congestion

$$
\text { in }
$$

our

Cities.www.ghanaweb.com/ghanahomepage/news archive.

[9] Gras, M.E.; Cunill, M.; Sullman, J.M.; Planes, M.; Aymerich, M.( 2004). Self-reported aberrant driving behaviour in a sample of Spanish drivers. Available from Internet:

<http://www.psychology.nottingham.ac.uk/IAAPdiv13/I
CTTP2004papers2/Individual\%20Differences/GrasB.pdf $>$.

[10] Iversen, H.H.; Rundmo, T. (2004). Attitudes towards traffic safety, driving behaviour and accident involvement among the Norwegian public, Ergonomics. 47(5): 555-572

[11] Oluwaseyi Joseph Afolabi and Gbadamosi Kolawole, T. (2017). Road traffic crashes in Nigeria: causes and consequences, The International Journal Transport \& logistics.17(42): 40-49.

[12] Titus M. Mweta, Grace A. Musa (2018). Effect of motor vehicle traffic congestion on the financial Performance of small and medium business enterprises in Nairobi County. International Journal of Advanced Research in Management and Social Sciences. 7(2):50-62. 